\title{
An investigation of long-distance propagation of gravity waves under CAWSES India Phase II Programme
}

\author{
N. Parihar ${ }^{1}$ and A. Taori ${ }^{2}$ \\ ${ }^{1}$ Dr. K. S. Krishnan Geomagnetic Research Laboratory, Indian Institute of Geomagnetism, Allahabad 221 505, India \\ ${ }^{2}$ National Atmospheric Research Laboratory, Gadanki 517 112, India \\ Correspondence to: N. Parihar (navindeparihar@gmail.com)
}

Received: 24 September 2014 - Revised: 13 April 2015 - Accepted: 23 April 2015 - Published: 18 May 2015

\begin{abstract}
Coordinated measurements of airglow features from the mesosphere-lower thermosphere (MLT) region were performed at Allahabad $\left(25.5^{\circ} \mathrm{N}, 81.9^{\circ} \mathrm{E}\right)$ and Gadanki $\left(13.5^{\circ} \mathrm{N}, 79.2^{\circ} \mathrm{E}\right)$, India to study the propagation of gravity waves in $13-27^{\circ} \mathrm{N}$ latitude range during the period June 2009 to May 2010 under CAWSES (Climate And Weather of Sun Earth System) India Phase II Programme. At Allahabad, imaging observations of $\mathrm{OH}$ broadband emissions and OI $557.7 \mathrm{~nm}$ emission were made using an all-sky imager, while at Gadanki photometric measurements of $\mathrm{OH}(6,2)$ Meinel band and $\mathrm{O}_{2}(0,1)$ Atmospheric band emissions were carried out. On many occasions, the nightly observations reveal the presence of similar waves at both locations. Typically, the period of observed similar waves lay in the 2.2-4.5 $\mathrm{h}$ range, had large phase speeds $\left(\sim 77-331 \mathrm{~m} \mathrm{~s}^{-1}\right)$ and large wavelengths ( 1194-2746 km). The images of outgoing long-wave radiation activity of the National Oceanic and Atmospheric Administration (NOAA) and the high-resolution infrared images of KALPANA-1 satellite suggest that such waves possibly originated from some nearby convective sources. An analysis of their propagation characteristics in conjunction with SABER/TIMED temperature profiles and Horizontal Wind Model (HWM 2007) wind estimates suggest that the waves propagated over long distances $(\sim 1200-2000 \mathrm{~km})$ in atmospheric ducts.
\end{abstract}

Keywords. Meteorology and atmospheric dynamics (Convective processes; Middle atmosphere dynamics; Waves and tides)

\section{Introduction}

Gravity waves (GWs) are an important dynamical feature of the mesosphere-lower thermosphere (MLT) region. GWs are created in the lower atmosphere by wind flow over uneven topography, convective activity, jet streams, geostrophic adjustments and other sources. GWs have periods of few minutes to hours, and their wavelengths range from tens of kilometres to hundreds of kilometres (Fritts and Alexander, 2003 and references cited therein). GWs propagate vertically as well as horizontally, and in the course of their vertical propagation from the lower atmosphere, their amplitude grows manifold (due to decreasing density). These waves become unstable at the MLT altitudes and ultimately they break thereby dissipating momentum and energy into the background atmosphere. As such, GWs play a crucial role in the momentum and energy budget of the MLT region. The wave dissipation affects winds and temperatures in the MLT region. GWs influence the density of reacting species/ambient temperature in the airglow-emitting region, and manifest themselves as the variations in airglow intensity (Noxon, 1978; Hines and Tarasick, 1994). Ground-based observations of different nightglow features from the MLT region have been extensively used in understanding gravity wave phenomenology (Takahashi et al., 1985; Taylor et al., 1995; Isler et al., 1997; Smith et al., 2000; Medeiros et al., 2007; Nielsen et al., 2012).

The background winds significantly influence the propagation of gravity waves. Depending upon their direction, the winds can induce a change in ray paths of gravity waves. The wind blowing in the direction of gravity wave supports their long-distance propagation, while gravity waves propagation against wind is significantly attenuated. Also, their 
propagation is subject to the thermal structure of the atmosphere. As a consequence, depending upon the background atmospheric conditions, gravity waves may exist as freely propagating waves or propagate in ducts, an atmospheric section flanked by regions of evanescence. At MLT heights, inhomogeneities in the background wind or temperature field or a combination of both give rise to atmospheric ducts. The ducts due to the variations in the mean wind field are called Doppler ducts, while those associated with strong discontinuities in the temperature field are called thermal ducts. And gravity waves trapped in these ducts can travel (without being considerably attenuated) to large horizontal distances before dissipating their energy and momentum to the background atmosphere; hence, these ducted waves are more likely to be detectable at large distance from their origin (Chimonas and Hines, 1986; Fritts and Yuan, 1989; Isler et al., 1997; Ding et al., 2003; Snively et al., 2007; Bageston et al., 2011). At low latitudes, such waves are more common in occurrence compared to those freely propagating (Isler et al., 1997). With reference to the matter presented in this paper, numerous bi-station/multi-station-based studies have been reported in past that address long-distance propagation of gravity waves in atmospheric ducts using airglow imaging observations. Using a tri-station airglow network between 42 and $44^{\circ}$ N, Stockwell and Lowe (2001) investigated the gravity wave field and found striking similarity in the characteristics of observed gravity wave spectrum. Ejiri et al. (2003) studied the propagation characteristics of gravity at two locations, Rikubetsu $\left(43.5^{\circ} \mathrm{N}, 143.8^{\circ} \mathrm{E}\right)$ and Shigaraki $\left(34.9^{\circ} \mathrm{N}, 136.1^{\circ} \mathrm{E}\right)$, Japan, separated by $\sim 1200 \mathrm{~km}$. Authors observed the poleward propagation of gravity waves during summer at both the sites and conjectured that the waves at the two sites were the same waves that possibly travelled in thermal ducts. Smith et al. (2003) reported observations of a mesospheric bore that travelled more than $1100 \mathrm{~km}$ from bi-station imaging and lidar measurements in $30^{\circ}-41^{\circ} \mathrm{N}$ latitude range. Medeiros et al. (2005) compared the characteristics of gravity waves observed at four sites located between 2 and $23^{\circ} \mathrm{S}$ and found that there is a preferential direction of motion of these waves from the continent towards the Atlantic Ocean. Using multi-instrument (imager, Na lidar, MF radar) observations in the range $31-32^{\circ} \mathrm{N}$ latitude, Kubota et al. (2006) observed a large-scale gravity wave of wavelength $\sim 673-774 \mathrm{~km}$, period $\sim 1.7 \mathrm{~h}$ and velocity $107-122 \mathrm{~m} \mathrm{~s}^{-1}$. Wrasse et al. (2006) investigated the propagation characteristics of gravity waves using the ray-tracing technique at four different stations - Cachoeira Paulista $\left(22.7^{\circ} \mathrm{S}, 45^{\circ} \mathrm{W}\right)$, Brazil, São João do Cariri $\left(7.4^{\circ} \mathrm{S}\right.$, $\left.36.5^{\circ} \mathrm{W}\right)$, Brazil, Tanjungsari $\left(6.9^{\circ} \mathrm{S}, 107.9^{\circ} \mathrm{E}\right)$, Indonesia and Shigaraki $\left(34.9^{\circ} \mathrm{N}, 136^{\circ} \mathrm{E}\right)$, Japan - and found that the source region of the gravity waves was located $1000 \mathrm{~km}$ away from the observational site on a few occasions. Recently Suzuki et al. (2013) reported observation of gravity waves that propagated in ducts over distances of $1800 \mathrm{~km}$ within the $31-44^{\circ} \mathrm{N}$ latitude range in Japan. All these investigations strongly suggest that gravity waves can propagate over large distances under suitable atmospheric conditions.

Coordinated measurements of the nightglow features from the MLT region were carried out over Allahabad $\left(25.5^{\circ} \mathrm{N}, 81.9^{\circ} \mathrm{E}\right)$ and Gadanki $\left(13.5^{\circ} \mathrm{N}, 79.2^{\circ} \mathrm{E}\right)$, India under CAWSES India Phase II Programme during April 2009May 2010 to study the propagation of gravity waves in the $13^{\circ}-27^{\circ} \mathrm{N}$ latitude range. Earlier, Mukherjee et al. (2010) studied the directional filtering effects of winds on the propagation of gravity waves over Allahabad using image data during February-May 2008, and found that the wave propagation was mostly directed towards the northeast direction. This preferential direction of gravity wave propagation towards the northeast is in line with the geometry of the two observing stations, with Gadanki located southwest of Allahabad.

In the present paper, the intensity measurements of $\mathrm{OH}$ broadband and OI $557.7 \mathrm{~nm}$ emission at Allahabad, and $\mathrm{OH}$ $(6,2)$ Meinel band and $\mathrm{O}_{2}(0,1)$ Atmospheric band at Gadanki during the period 2009-2010 has been analysed to study the long-distance propagation of gravity waves having period of an hour or more. In some nights, similar waves were seen at the MLT heights over Allahabad and Gadanki.

\section{Experimental set up and data}

Under CAWSES (Climate And Weather of Sun Earth System) India Phase II Programme, coordinated measurements of nightglow features from the MLT region were carried out using the All-Sky Imager (ASI) and Mesosphere Lower Thermosphere Photometer (MLTP) over Allahabad $\left(25.5^{\circ} \mathrm{N}\right.$, $\left.81.9^{\circ} \mathrm{E}\right)$ and Gadanki $\left(13.5^{\circ} \mathrm{N}, 79.2^{\circ} \mathrm{E}\right)$, respectively, during June 2009-May 2010. The two stations are separated in latitude by $\sim 12^{\circ}$ (aerial distance more than $1200 \mathrm{~km}$ ) with Allahabad located north-northeast of Gadanki. Figure 1 presents the location of these two airglow observing stations.

\subsection{Imaging observations at Allahabad}

Nightglow observations of OH broadband and OI $557.7 \mathrm{~nm}$ emission were carried out at Allahabad. The imaging system (made by Keo Scientific Ltd., Canada) consisted of a $180^{\circ}$ field-of-view fish eye lens, telecentric optical system, 6-filter wheel assembly, re-imaging optical system, a backilluminated CCD sensor and the imager control system. The filter wheel assembly and CCD detector were thermoelectrically maintained at 25 and $-53{ }^{\circ} \mathrm{C}$, respectively (Mukherjee et al., 2010). Because of heavy contamination by city lights at low elevation angles, the field of view was reduced by a circular baffle. At the $\mathrm{OH} / \mathrm{O}_{2}$ emission heights, the imager was able to cover fairly airglow information over $\pm 1.3^{\circ}$ latitude/longitude of Allahabad. The $\mathrm{OH}$ broadband nightglow emissions were monitored using a $190 \mathrm{~nm}$ broadband optical filter $(720-910 \mathrm{~nm})$ with $87 \%$ transparency and a notch at 


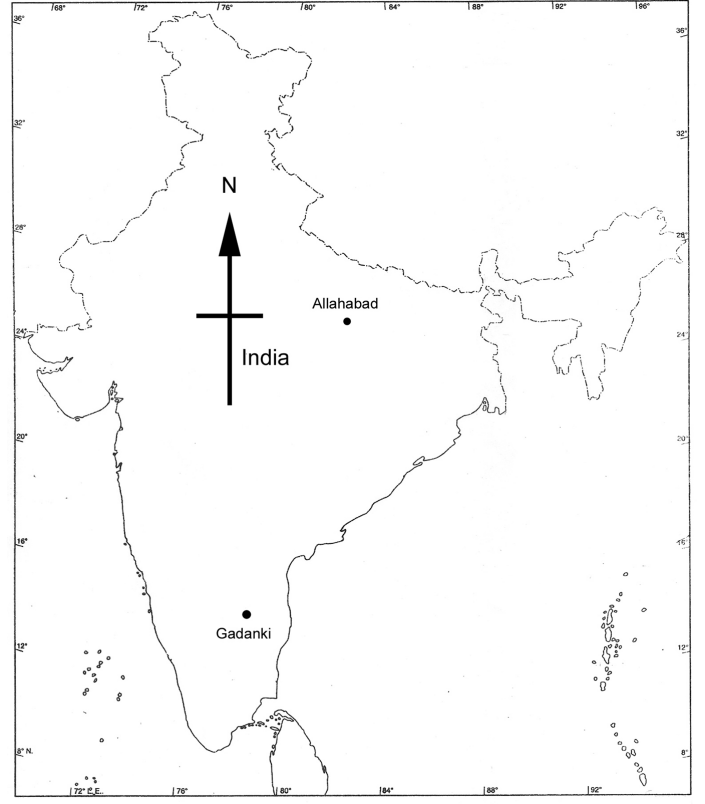

Figure 1. Location of Allahabad and Gadanki in the Indian subcontinent.

$868 \mathrm{~nm}$ - to exclude contribution from the $\mathrm{O}_{2}(0,1)$ Atmospheric band emission. An optical filter having central wavelength of $557.7 \mathrm{~nm}$, bandwidth of $\sim 1.8 \mathrm{~nm}$ and transparency of $55 \%$ was used to study the OI $557.7 \mathrm{~nm}$ emission. For each emission, the exposure time was $90 \mathrm{~s}$ on some occasions, and was $120 \mathrm{~s}$ on other nights. Sampling interval varied between 2 and $9 \mathrm{~min}$. On most occasions, 4 min of sampling interval was observed.

Using the imaging database, the average intensity information contained in a square bin (subsuming to a circular field of view of $4^{\circ}$ ) was retrieved for the five positions in the image field that correspond to zenith (named Allahabad, ALD), and to vertical projections from the airglow layer(s) to the geographical locations $1^{\circ}$ north, south, east and west of Allahabad (named NoALD, SoALD, EoALD and WoALD, respectively). This difference of $2^{\circ}$ between the off-zenith extremes in latitude and longitude (at latitude of Allahabad) corresponds to $\sim 220$ and $\sim 200 \mathrm{~km}$, respectively. Using this intensity and timestamp information of corresponding image, time series for each of the sample places were constructed. Such procedure was adopted for both $\mathrm{OH}$ and OI $557.7 \mathrm{~nm}$ imaging database. Figure 2 presents a typical example of the variation of two emission intensities along the zenith and for all the four off-zenith positions on the night of 22-23 October 2009 using this process.

\subsection{Photometric observations at Gadanki}

Nightglow measurements of $\mathrm{P}_{1}(2)$ and $\mathrm{P}_{1}$ (4) lines of $\mathrm{OH}(6$, 2) Meinel band and P-branch spectrum of $\mathrm{O}_{2}(0,1)$ Atmospheric band at 866 and $868 \mathrm{~nm}$ were carried out at Gadanki
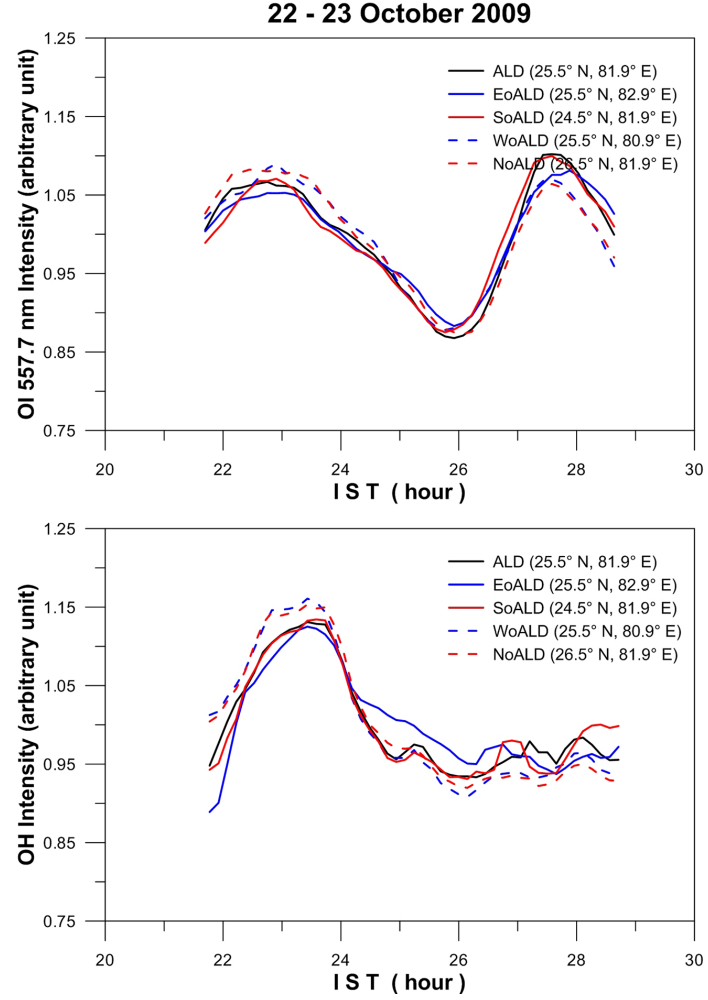

Figure 2. Nocturnal variation of $\mathrm{OH}$ broadband and OI $557.7 \mathrm{~nm}$ emission intensity at different sampling positions over Allahabad on 22-23 October 2009.

$\left(13.5^{\circ} \mathrm{N}, 79.2^{\circ} \mathrm{E}\right)$, India using MLTP. MLTP consisted of three $f / 2$ lens systems having field of view of $4^{\circ}$, a filter assembly that is thermoelectrically maintained at $24^{\circ} \mathrm{C}$ and capable of hosting seven filters, and which utilizes a GaAsbased Hamamatsu R943-02 photomultiplier tube for photon detection (thermoelectrically cooled to $-40^{\circ} \mathrm{C}$ ) (Taori et al., 2011). The $\mathrm{P}_{1}(2)$ and $\mathrm{P}_{1}(4)$ lines of $\mathrm{OH}(6,2)$ Meinel band and P-branch spectrum of $\mathrm{O}_{2}(0,1)$ Atmospheric band at 866 and $868 \mathrm{~nm}$ were monitored using filters of central wavelength $\sim 840,846,866$ and $868 \mathrm{~nm}$. The filters had narrow bandwidth of $\sim 0.4 \mathrm{~nm}$ and transmittances between 40 and $70 \%$. The background measurements at $857 \mathrm{~nm}$ were also carried out. The observation cycle consists of $10 \mathrm{~s}$ exposure of each filter and repeating the sequence at $90 \mathrm{~s}$ cadence. MLTP was operated for observations along the zenith only.

An absolute intensity calibration is not available, but efforts with a standard tungsten ribbon lamp and $\mathrm{MgO}$ diffusor are underway to produce absolute units in future. But even without an absolute intensity calibration, normalized time series are suitable for comparisons between different parts of the field of view, or between different airglow emissions. During the period June 2009 to May 2010 at each station, several nights of observational database existed; however, due to significant differences in sky-observing condition over Allahabad and Gadanki, very limited coincidences were ob- 
served. Only the coincidental nights characterized by good weather conditions (i.e. clear-sky and low level of moonlight) and having the duration of continuous observation of $4 \mathrm{~h}$ or more were considered in the present study. Complying with these conditions, the nightglow data of eight nights on the whole was available for investigating the long-distance propagation of gravity waves. Here, the characteristics of gravity waves have been estimated assuming that $\mathrm{OH}$ Meinel band, the $\mathrm{O}_{2}$ Atmospheric band and the $\mathrm{OI} 557.7 \mathrm{~nm}$ emission peak are located at 87,94 and $97 \mathrm{~km}$, respectively.

In order to examine the propagation conditions of the common wave features that are observed at the two optical sites, the wind predictions of Horizontal Wind Model 2007 (HWM-07) (Drob et al., 2008) (due to lack of proper wind measurements) and the temperature profiles measured by SABER (Sounding of the Atmosphere using Broadband Emission Radiometry) instrument on-board NASA's Thermosphere Ionosphere Mesosphere Energetics and Dynamics (TIMED) satellite (Mertens et al., 2001) have been used. As convection is an important source of gravity waves in the Tropics, the contour images of OLR (outgoing long-wave radiation) of National Oceanic and Atmospheric Administration (NOAA) (Liebmann and Smith, 1996) and the highresolution infrared image of KALPANA-1 satellite (Prakash et al., 2011) have been utilized to identify the possible source of the common waves.

\section{Identification of wave periods and estimation of their propagation characteristics}

Firstly to enhance the short-period gravity wave induced features, the long-term tide-like trend present in intensity database was removed (wherever it was possible). In this detrending process, (i) a sinusoidal least square fit of form $[A \sin (2 \pi t / T+\varphi)+c]$ was forced on the time series of emission intensity ( $A$ is amplitude of the wave; $T$ is wave period and is either 8,12 or $24 \mathrm{~h} ; \varphi$ represents the phase of wave, and $c$ is a constant term), (ii) root mean square error (RMSE) of the sinusoidal fit is estimated for each value of $T$ and the fit with the least value of RMSE is assumed to be the tidal harmonic present in the intensity data, and (iii) this tidal contribution is then removed from the original series so as to get a residual series. Parihar et al. (2013) have found that this fit successfully explains the long-term tidal trend in the MLT region nightglow intensity and temperatures. Whenever it was not possible to identify distinctly the tidal trend, the linear trend present in the intensity database was removed. For simplicity, the waves with periods of $6 \mathrm{~h}$ or more are considered as the long-period oscillations. After this detrending, Lomb-Scargle analysis of residual time series was performed to infer the spectral components of gravity waves in $\mathrm{OH}$ and OI $557.7 \mathrm{~nm}$ measurements (Lomb, 1976). Similar steps were adopted for $\mathrm{OH}(6,2)$ Meinel band and $\mathrm{O}_{2}(0,1)$ Atmospheric band intensity measurements over Gadanki as
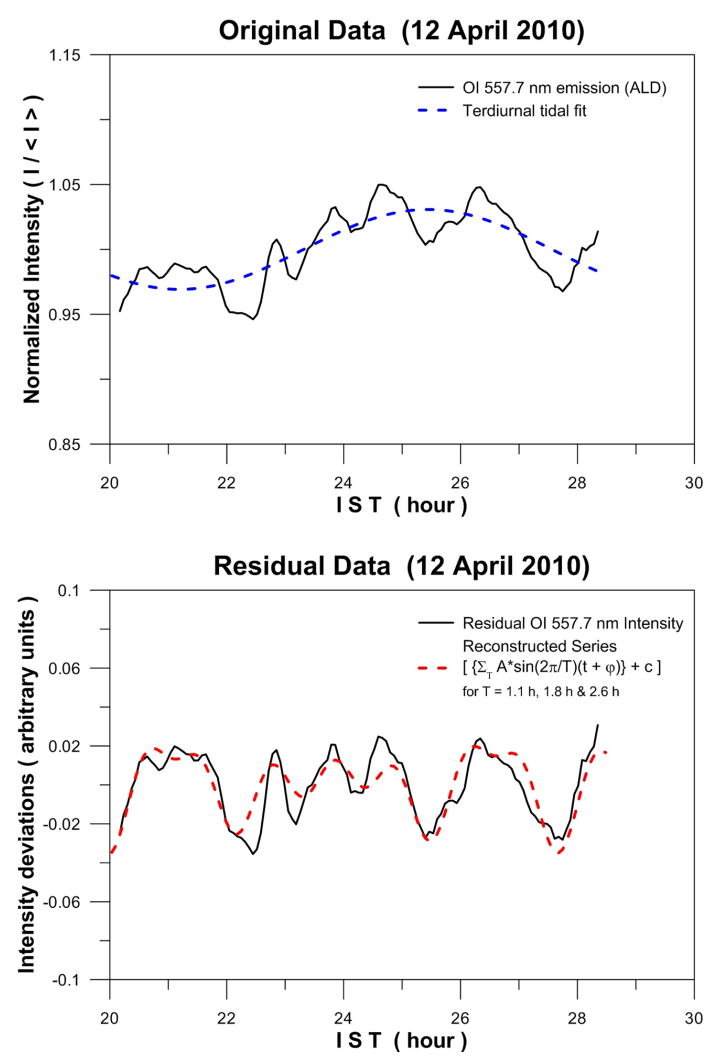

Figure 3. Nocturnal variation of OI $557.7 \mathrm{~nm}$ emission intensity on 12-13 April 2010 (top panel). The broken curve represents the sinusoidal least square fit applied to OI $557.7 \mathrm{~nm}$ emission intensity. The variation of residual intensity obtained after removal of terdiurnal tidal trend from original time series of OI $557.7 \mathrm{~nm}$ emission intensity (bottom panel).

well. Such analysis procedure of identifying the short-period wave harmonics has been described in detail by Parihar and Mukherjee (2014).

A typical example of such analysis for OI $557.7 \mathrm{~nm}$ intensity on 12-13 April 2010 is presented in Fig. 3. On this night, several short-period oscillations were observed in the nocturnal variation of OI $557.7 \mathrm{~nm}$ emission intensity (see top panel of Fig. 3). Sinusoidal least square fitting analysis of OI $557.7 \mathrm{~nm}$ intensity series suggested the presence of a terdiurnal tide, and this tidal feature is shown by a broken curve in the top panel of Fig. 3. This terdiurnal trend was removed from original time series to form a residual series (represented by a solid curve in the bottom panel of Fig. 3). An enhancement of short-period features can clearly be seen in the residual series. Lomb-Scargle analysis of this residual time series was performed and it suggested the presence of $1.1,1.8$ and $2.6 \mathrm{~h}$ waves.

In the present study, the amplitude and phase information of a wave feature has been computed using the technique described in great detail by Zhang et al. (1993). Initially for the first dominant frequency, $\omega$, a model of form 
Table 1. Gravity waves observed over Allahabad and Gadanki during the period June 2009 to May 2010. At Allahabad, the waves that were consistently identified at all sample locations are listed.

\begin{tabular}{lll|ll}
\hline & \multicolumn{4}{c}{ Period of observed gravity waves (in h) } \\
\cline { 2 - 5 } Date & \multicolumn{2}{c}{ Allahabad } & \multicolumn{1}{c}{ Gadanki } \\
\cline { 2 - 5 } & OH & OI 557.7 nm & OH $(6,2)$ & $\mathrm{O}_{2}(0,1)$ \\
\hline 23-24 June 2009* & $1.6,2.2$ & $1.9,2.6,4.4$ & 4.3 & 4.3 \\
24-25 June 2009 & $1.5,3.1$ & $1.9,4.4$ & $0.7,1.0,2.6,4.5$ & $1.0,2.6,4.5$ \\
22-23 October 2009 & $2.2,4.1$ & $2.6,4.8$ & 3.7 & 4.2 \\
23-24 October 2009 & $1.3,1.6,2.3,4.0$ & $1.6,4.0$ & $1.4,1.8,2.2,3.1,5.6$ & $1.4,1.8,2.2,3.1,5.6$ \\
12-13 April 2010 & $1.8,4.7$ & $1.1,1.8,2.6$ & Nil & Nil \\
15-16 April 2010 & $1.9,2.6$ & $2.2,3.7$ & 3.5 & 3.5 \\
16-17 April 2010 & $1.2,3.1$ & $1.3,2.1,3.2$ & Nil & 1.8 \\
12-13 May 2010 & $1.3,1.8,4.2$ & No observations & $0.6,2.2$ & $0.6,1.2$ \\
\hline
\end{tabular}

* Observations affected by cloudy sky during 22:00-23:18 and 02:00-03:00 IST.

$Z=a \cos \omega(t-\tau)+b \sin \omega(t-\tau)$ is forced on the residual time series, $R$ (where $a, b$ and $\tau$ are the unknown constants). By the method of least squares and following Lomb (1975), $a, b$ and $\tau$ are estimated. Now, $Z$ can be expressed as $Z=$ $A \cos (\omega t-\varphi)$ - where $A$ is amplitude and $\varphi$ is phase, and are given by $A(\omega)=\sqrt{ }\left(a^{2}+b^{2}\right)$ and $\varphi(\omega)=\tan ^{-1}(b / a)+\omega \tau$ (see original article for a detailed mathematical formulation). Next, this first dominant wave is removed and the same process is repeated to estimate the amplitude and phase of second harmonic, and so on. Using the amplitude and phase information of all waves, a time series was reconstructed. One such example of reconstruction for OI $557.7 \mathrm{~nm}$ residual intensity on 12-13 April 2010 is shown by a broken curve in the bottom panel of Fig. 3. A good correspondence between residual database and reconstructed series can clearly be observed.

All of the above steps are repeated for each sampling position to infer the amplitude and phase information of each spectral component. The phase $\varphi$ of a wave at any point $r$ in space is $k \cdot r$ where $k$ is its wavenumber. Using the geometrical relationship between the wave direction and its phase at different equidistant positions on the annular field of view, Zhang et al. (1993) have described a method to compute its horizontal propagation characteristics, i.e. the wave direction, the horizontal wavelength and speed. Suppose $\varphi_{I}$ and $\varphi_{J}$, respectively, be the phase at two positions $P_{I}$ and $P_{J}$ located on the annular field of view of radius $r$ at angle $I$ and $J$, respectively, measured from east to north, and $\theta$ be the wave direction, then these authors arrived at the following relationship:

$\varphi_{I}-\varphi_{J}=a^{\prime} r(\sin I-\sin J)+b^{\prime} r(\cos I-\cos J)$,

where $a^{\prime}=k \sin \theta$ and $b^{\prime}=k \cos \theta$.

Now, unknown coefficients $a^{\prime}$ and $b^{\prime}$ can be determined from the linear relationship between $(\sin I-\sin J) / \varphi_{I}-\varphi_{J}$ and $(\cos I-\cos J) / \varphi_{I}-\varphi_{J}$. In principle, two unknowns can be evaluated from the phase information of at least three sec- tors. Once $a^{\prime}$ and $b^{\prime}$ are known, the horizontal wavenumber, $k$, and the wave direction, $\theta$, can be derived from the following expressions:

$k=\sqrt{ }\left(a^{\prime 2}+b^{\prime 2}\right)$,

$\theta=\tan ^{-1}\left(a^{\prime} / b^{\prime}\right)$.

And then the horizontal wavelength, $\lambda$, and phase speed, $v$, can be evaluated. In the present study, using this technique, the propagation characteristics of a wave have been deduced from its phase information at four off-zenith sampling positions mentioned earlier and assuming $r=110 \mathrm{~km}$.

\section{Observations and results}

Table 1 summarizes the gravity wave components present in the residual intensity data of different emission features (namely $\mathrm{OH}$ and $\mathrm{OI} 557.7 \mathrm{~nm}$ emission at Allahabad and in $\mathrm{OH}$ and $\mathrm{O}_{2}$ heights at Gadanki) on a few nights during June 2009-May 2010. Generally, the wave variability over zenith and different off-zenith measurements at Allahabad showed similarity; however, occasionally not all wave features were present at all five positions. Such behaviour was markedly observed at $\mathrm{OH}$ heights on 24-25 June 2009 and 16-17 April 2010. On 24-25 June 2009, the $\mathrm{OH}$ intensity along the zenith was marked by $\sim 0.7,1.0,1.5$ and $3.1 \mathrm{~h}$ waves but the offzenith measurements did not show any signs of 0.7 and $1.0 \mathrm{~h}$ waves. However, at OI $557.7 \mathrm{~nm}$ heights, $\sim 1.9$ and $\sim 4.4 \mathrm{~h}$ waves were consistently identified at all places. A graphical illustration of such dissimilar behaviour along different directions at $\mathrm{OH}$ heights for 16-17 April 2010 is shown in Fig. 4. On this particular night, $\sim 1.2$ and $\sim 3.1 \mathrm{~h}$ wave was common everywhere but other wave features were unrelated. In addition, (i) $\sim 0.6 \mathrm{~h}$ wave was observed along WoALD (ii) $\sim 0.9 \mathrm{~h}$ wave was present along zenith, EoALD and SoALD, and (iii) a $1.8 \mathrm{~h}$ wave was seen along NoALD, 
Allahabad ( 16 - 17 April 2010)

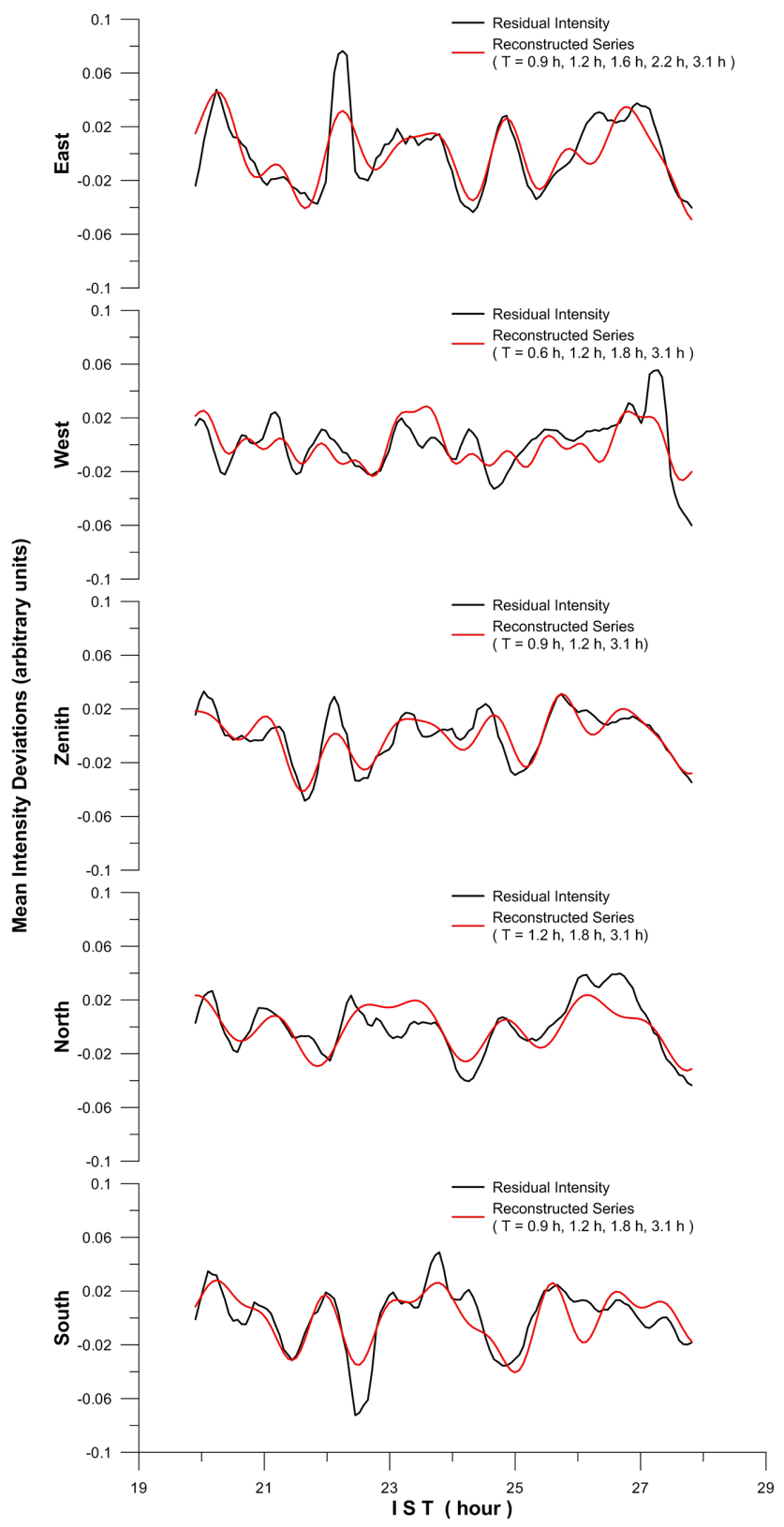

Figure 4. Nocturnal variation of the residual intensity of $\mathrm{OH}$ broadband emission on 16-17 April 2010 along different directions.

WoALD and SoALD. Also shown along with the individual plots in Fig. 4 are the series reconstructed using these spectral components. Only the waves that were consistently observed at all sample places over Allahabad have been listed in Table 1.

Overall, the nocturnal behaviour of different emission intensities at both locations was defined by gravity wave induced oscillations having period in the range of 0.6-5.6 h. On most occasions, a similar wave can be seen at both lo- cations. On 23-24 June 2009, a $\sim 4.3 \mathrm{~h}$ wave appears to be common at Allahabad and Gadanki. A $\sim 4.5 \mathrm{~h}$ wave was seen at OI $557.7 \mathrm{~nm}$ heights at Allahabad and at $\mathrm{OH} / \mathrm{O}_{2}$ altitudes at Gadanki on 24-25 June 2009. Similarly, a $\sim 3.5 \mathrm{~h}$ wave was present on 15-16 April 2010 in OI $557.7 \mathrm{~nm}$ intensity at Allahabad and at $\mathrm{OH} / \mathrm{O}_{2}$ intensities at Gadanki. On 23-24 October 2010, a $\sim 2.2 \mathrm{~h}$ wave was found to be common at $\mathrm{OH}$ altitudes over Allahabad and at $\mathrm{OH} / \mathrm{O}_{2}$ heights at Gadanki. The minor difference $(\sim 8-10 \%$ or less) in the period of the wave at the two locations can be attributed to the differences in the data sampling rate and the complex behaviour of the MLT region. Such small differences can be caused by Doppler shifting of wave periods under the influence of variable background wind conditions over such large distances. Generally, the common wave was the main contribution to the temporal variation at both locations. On 24 25 June 2009 and 15-16 April 2010, this contribution was in the $54-89 \%$ range. A lesser contribution $(\sim 20 \%)$ of $2.2 \mathrm{~h}$ wave to the observed variability was present on 23-24 October 2009 at Gadanki.

\subsection{Case study of 24-25 June 2009}

Figure $5 \mathrm{a}$ and $\mathrm{b}$ depict the behaviour of normalized intensity of different emission feature at Allahabad and Gadanki, respectively, on this night. At Allahabad, sinusoidal best fitting analysis suggests the existence of a semidiurnal tide in $\mathrm{OH}$ broadband emission, while a $\sim 4.5 \mathrm{~h}$ wave can clearly be observed in OI $557.7 \mathrm{~nm}$ intensity from the Fig. 5a. It is worth mentioning here that clear sky conditions existed between 21:00 and 03:00 IST over Allahabad, resulting in $\sim 5.5 \mathrm{~h}$ good observations. Subsequently the semidiurnal trend was removed from $\mathrm{OH}$ intensity data over Allahabad. Tidal trend could not be identified in OI $557.7 \mathrm{~nm}$ emission; hence, its intensity data were detrended with respect to the corresponding mean. On the other hand, $\mathrm{OH}$ and $\mathrm{O}_{2}$ intensity data at Gadanki showed the presence of a diurnal tide, and same were eliminated from the intensity database. Figure $5 \mathrm{c}$ and $\mathrm{d}$ present the variation of residual intensity data at Allahabad and Gadanki, respectively. Using the residual data, the gravity wave components were inferred (see Table 1). The broken curve in the individual plots represents the intensity series reconstructed using different spectral components. Overall, a fair congruence between observed variations of intensity and reconstructed series can be seen.

At Allahabad, a mixture of wave having period of $\sim 1.5$ and $\sim 3.1 \mathrm{~h}$ was found at $\mathrm{OH}$ heights, while at OI $557.7 \mathrm{~nm}$ altitude, the waves having period of $\sim 1.9$ and $\sim 4.4 \mathrm{~h}$ were seen. Such striking difference in the observed wave periodicities suggests that the waves observed at $\mathrm{OH}$ altitudes probably dissipated below OI $557.7 \mathrm{~nm}$ layer or their vertical propagation was not supported, and the 1.9 and $4.4 \mathrm{~h}$ waves at OI 557.7 heights were probably represented ducted wave motions. At $\mathrm{OH}$ heights, a strong difference in the wave observations existed among the different sample locations, i.e. 

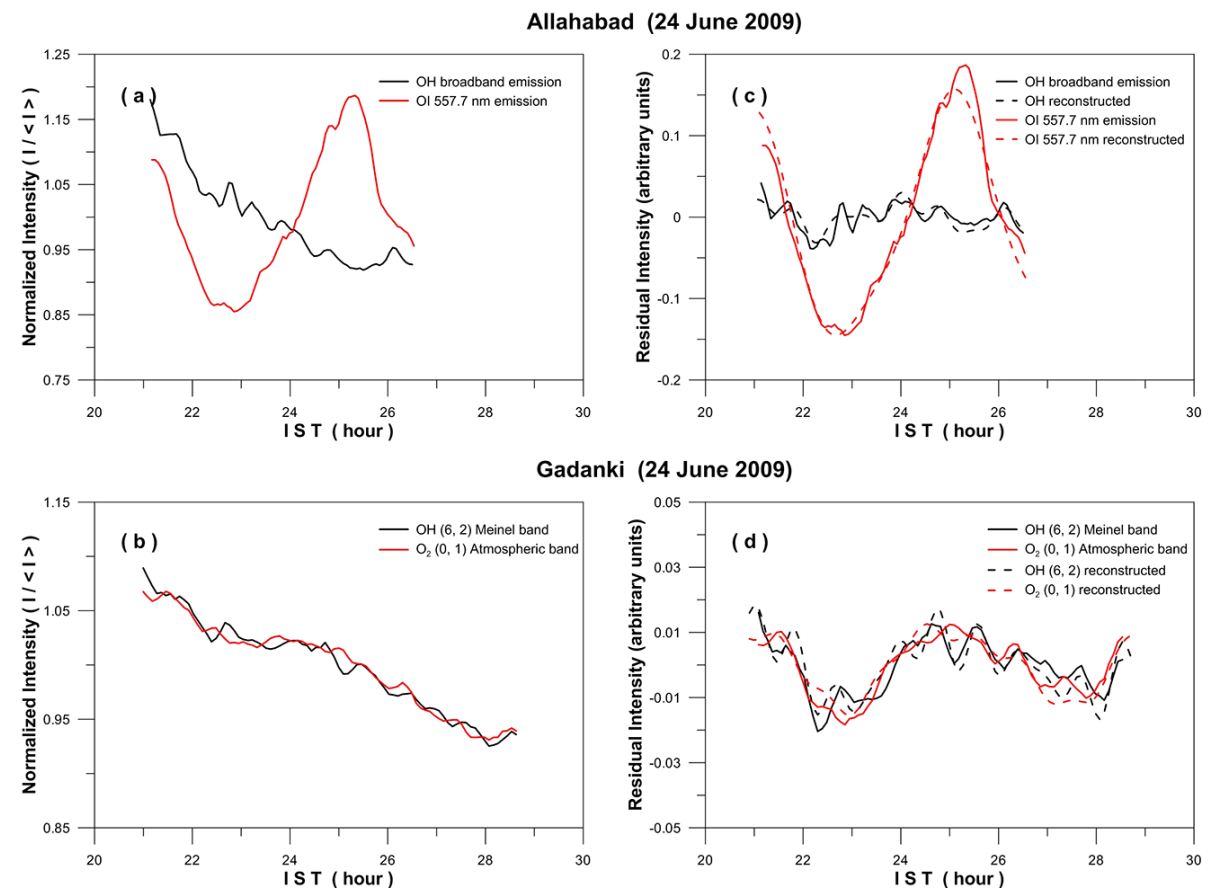

Figure 5. Nocturnal variation of different emission features over Allahabad and Gadanki on 24-25 June 2009: (a) and (b) depict the behaviour of normalized intensity at Allahabad and Gadanki, respectively, while the variation of residual intensity is shown in (c) and (d). The broken curves represent the intensity series reconstructed using different spectral components.

the waves present along the zenith were entirely different from those found along off-zenith measurements. In addition to 1.5 and $3.1 \mathrm{~h}$ waves, two waves of period $\sim 0.7$ and $\sim 1.0 \mathrm{~h}$ were seen along the zenith but were not observed along EoALD and SoALD. A similar situation existed for EoALD and SoALD measurements too. At OI $557.7 \mathrm{~nm}$ altitudes, however, uniformity in the wave observations along the different directions was noticed, i.e. the $\sim 1.9$ and $\sim 4.4 \mathrm{~h}$ waves were seen at all directions. All these observations suggest that the 1.9 and $4.4 \mathrm{~h}$ waves were most likely of remote origin and their propagation was probably ducted. At Gadanki, a mixture of $\sim 0.7,1.0,2.6$ and $4.5 \mathrm{~h}$ waves was found to define the variation of $\mathrm{OH}$ intensity. Out of these four waves, the $0.7 \mathrm{~h}$ wave was not observed at $\mathrm{O}_{2}$ heights and might be probably dissipative in nature, while the remaining three waves (namely 1.0, 2.6 and $4.5 \mathrm{~h}$ ) were seen at $\mathrm{O}_{2}$ altitude. While the $4.5 \mathrm{~h}$ wave simultaneously marked its presence at $\mathrm{OH}$ and $\mathrm{O}_{2}$ heights, the waves of period $\sim 1.0$ and $\sim 2.6 \mathrm{~h}$ were found to be vertically propagating with a phase speed of $\sim 24$ and $\sim 31 \mathrm{~m} \mathrm{~s}^{-1}$, respectively. In the course of their propagation from $\mathrm{OH}$ to $\mathrm{O}_{2}$ layer, their amplitude was found to increase by a factor of $\sim 1.5$. Thus, the 0.7 and $1.0 \mathrm{~h}$ waves observed over Allahabad were of different origin than those of the same period observed at Gadanki, and the $4.5 \mathrm{~h}$ wave might be a common wave that propagated over long distances at $\mathrm{O}_{2}-$ OI $557.7 \mathrm{~nm}$ altitudes from its origin.

\section{Characteristics of the $4.5 \mathrm{~h}$ common wave}

The minimum corresponding to this wave appeared nearly simultaneously over Gadanki and Allahabad around 23:00 IST. As the $4.5 \mathrm{~h}$ wave was seen at both $\mathrm{OH}$ and $\mathrm{O}_{2}$ heights simultaneously over Gadanki, it appears that either this wave had large vertical wavelength or the wave was trapped in a duct that subsumed the $\mathrm{OH}$ and $\mathrm{O}_{2}$ layers. Using the technique discussed in Sect. 3, the phase information of this wave and its propagation characteristics were inferred over Allahabad. Its phase was found to be $21,42,37$ and $18^{\circ}$, respectively at east, north, west and south sampling positions. It was found to propagate along the $326 \pm 6^{\circ}$ azimuth, i.e. towards the northwest of Allahabad, and had a horizontal wavelength of $\sim 2746 \pm 264 \mathrm{~km}$. Due to lack of proper wind measurements, the Doppler effects could not be subtracted from the estimated wave parameters and the apparent phase speed of this wave was estimated to be $\sim 170 \pm 16 \mathrm{~m} \mathrm{~s}^{-1}$. Regarding its source, the propagation of wave to the northwest over Allahabad suggests the source region to be located to the southeast.

The latent heat release in deep convection is an important source of gravity wave excitation over Tropics and subtropics. Also, since June is marked by the onset of monsoon over the Indian subcontinent, enhanced convective activity should be expected. Hence, it is possible that convection might be the source of this wave. Studies by Preusse et al. (2001) on the global distribution of gravity wave ac- 


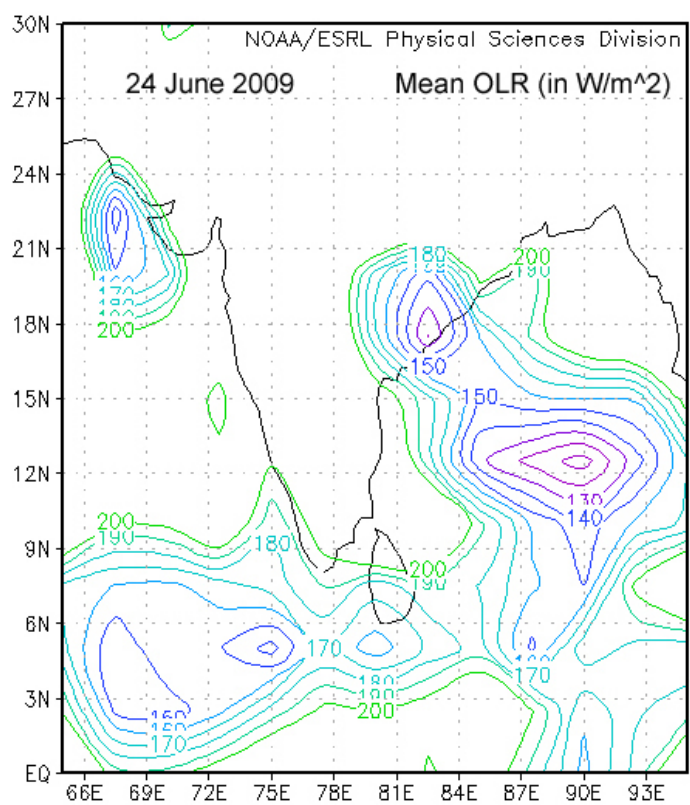

Figure 6. NOAA's contour image of outgoing long-wave radiation activity over Indian subcontinent on 24-25 June 2009.

tivity using the database of temperature and mixing ratio of tropospheric water vapour acquired by CRyogenic Infrared Spectrometers and Telescopes for the Atmosphere (CRISTA) experiment supports this idea. Preusse et al. (2001) found strong gravity wave activity over the equator and subtropics. The investigation of water vapour mixing ratio by these authors revealed that the deep convection indeed generated these waves. Outgoing long-wave radiation (OLR) is a good indicator of convective activity. NOAA's (National Oceanic and Atmospheric Administration) contour image of outgoing long-wave radiation activity (www.esrl.noaa.gov/ psd/gridded/data.uninterp_OLR.html, Liebmann and Smith, 1996) over the Indian subcontinent on 24 June 2009 (shown in Fig. 6) suggest deep convection of $106 \mathrm{Wm}^{-2}$ centred on $12.5^{\circ} \mathrm{N}, 90^{\circ} \mathrm{E}$, and probably was the source of this wave. Figure 7 shows the high-resolution infrared image of KALPANA-1 satellite at 11:30 IST for 24 June 2009. The presence of a gigantic mesoscale convective system in a grid of $\sim 12-20^{\circ} \mathrm{N}$ latitude and $83-89^{\circ} \mathrm{E}$ longitude can clearly be observed, and confirms the message from the NOAA's OLR image. This idea of convective forcing is supported by the facts that this convective body is (i) aligned nearly with the wave propagation direction, and (ii) nearly equidistant from the two observing stations and the wave minimum occurred simultaneously at both sites (around 22:45 IST).

Modelling studies on the convectively generated gravity waves by Vadas and Fritts (2001) and Vadas et al. (2009) indicate that a continuous spectrum of gravity waves is excited by a convective body and has a maximum that depends on the spatial feature of the convective forcing given by $T_{\mathrm{c}}=T_{\mathrm{b}}\left[\left(D_{\mathrm{H}} / D_{\mathrm{Z}}\right)^{2}+1\right]^{1 / 2}$. Here, $T_{\mathrm{c}}$ is the characteristic

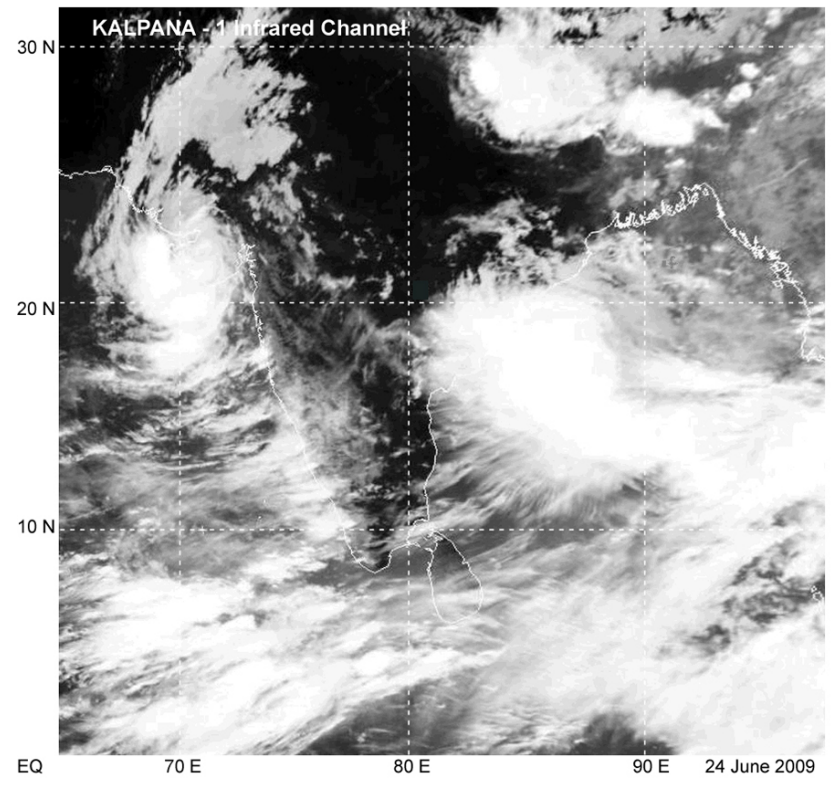

Figure 7. High-resolution infrared image of KALPANA-1 satellite for 24-25 June 2009.

period of this maximum, $T_{\mathrm{b}}$ is the Brunt-Vaisäla period, $D_{\mathrm{H}}$ and $D_{\mathrm{Z}}$ represent the full horizontal extent and full vertical depth of the convective forcing. Using SABER/TIMED temperature measurements, the Brunt-Vaisäla period, $T_{\mathrm{b}}$, was estimated to be $\sim 4.3 \mathrm{~min}$. Based on OLR and KALPANA1 images the horizontal extent of this convective body, $D_{\mathrm{H}}$, is assumed to be $\sim 900 \mathrm{~km}$. If we assume that this convective forcing is located below tropopause and its depth is 1$3 \mathrm{~km}$ less than tropopause altitude, namely $\sim 18 \mathrm{~km}$ (Venkat Ratnam et al., 2005), its full vertical depth, $D_{\mathrm{Z}}$, can be taken as $15 \mathrm{~km}$. The tropopause altitude of around $18 \mathrm{~km}$ is based on the investigation of CHAMP/GPS (CHallenging Mini satellite Payload/Global Positioning System) radio occultation measurements in $15-20^{\circ} \mathrm{N}$ latitude during $2001-$ 2004 by Venkat Ratnam et al. (2005). Using these inputs, the characteristic period comes out to be $4.3 \mathrm{~h}$. Thus, this $4.5 \mathrm{~h}$ wave was possibly excited by this mesoscale convective system. Investigations by Vincent et al. (2013) suggest that the waves created by such convective systems can reach the MLT heights within $1-2 \mathrm{~h}$ of their generation and propagate laterally $\sim 200-250 \mathrm{~km}$ from the epicentre of convection during this duration. It is therefore likely that this $4.5 \mathrm{~h}$ wave overcame the mean critical level wind filtering in the course of its propagation to the MLT region due to its large phase speed.

Using SABER/TIMED temperature measurements and HWM-07 wind estimates, the squared vertical wave number, $\mathrm{m}^{2}$, profile for this $4.5 \mathrm{~h}$ wave was examined and is shown in Fig. 8. The top and bottom panel, respectively, represents results for Allahabad and Gadanki. Also shown are the profiles of the square of Brunt-Vaisäla frequency, $N^{2}$, and the HWM wind, $U$, along the wave propagation direction. As 

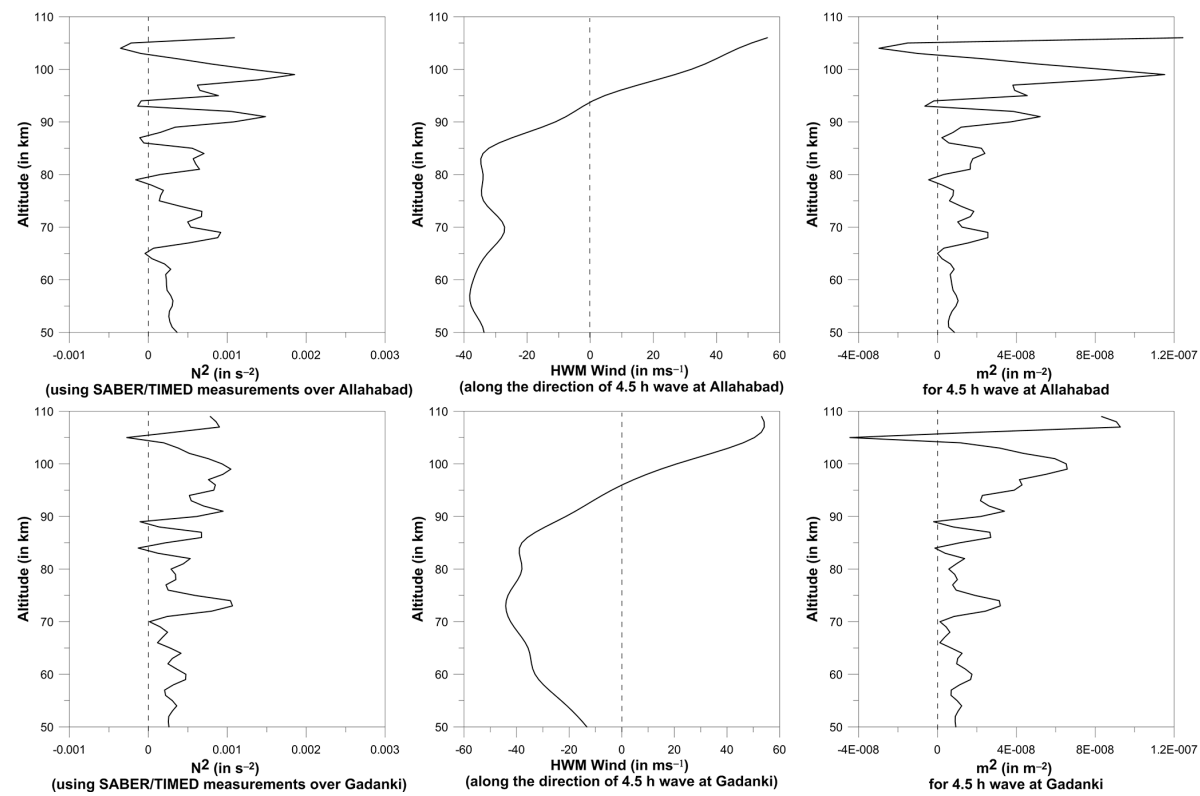

Figure 8. Altitude variation of the square of Brunt-Vaisäla frequency $\left(N^{2}\right)$ (left panel), the HWM wind $(U)$ along the propagation direction of $4.5 \mathrm{~h}$ wave (middle panel), and the squared vertical wave number $\left(\mathrm{m}^{2}\right)$ (right panel). Results for Allahabad and Gadanki are presented in the top and bottom panel, respectively.

the horizontal propagation characteristics of this $4.5 \mathrm{~h}$ wave were not known at Gadanki, the wave is assumed to propagate towards the west (being radially directed from a source at $13^{\circ} \mathrm{N}, 89^{\circ} \mathrm{E}$ ) at a speed of $155 \mathrm{~m} \mathrm{~s}^{-1}$ (the difference between apparent speed at Allahabad and HWM wind component). Negative zones in the $N^{2}$ profile at both locations can be noticed, thereby rejecting the idea of vertical propagation of this wave at both observing sites. Over Allahabad, a prominent atmospheric duct between 93 and $104 \mathrm{~km}$ in the $\mathrm{m}^{2}$ profile suggests that this wave propagated in a duct at the OI $557.7 \mathrm{~nm}$ emission heights. Over Gadanki, a fairly large regime between 89 and $105 \mathrm{~km}$, subsuming a part of $\mathrm{OH}$ layer and entire $\mathrm{O}_{2}$ atmospheric band emission layer, can be seen to exist in the $\mathrm{m}^{2}$ profile that can support the propagation of this wave. On the whole, the investigation of $\mathrm{m}^{2}$ profile explains, to a fair extent, (i) the observation of this wave at OI $557.7 \mathrm{~nm}$ heights at Allahabad and at both $\mathrm{OH} / \mathrm{O}_{2}$ heights at Gadanki; and (ii) that the wave is ducted. In summary, a large mesoscale convective system centred on $\sim 13^{\circ} \mathrm{N}, 90^{\circ} \mathrm{E}$ may have generated this $4.5 \mathrm{~h}$ wave that propagated in atmospheric duct at the MLT heights over large distances and was seen at Gadanki and Allahabad.

A nearly similar case was observed on 23-24 June 2009 when a $4.3 \mathrm{~h}$ common wave was observed at Gadanki (in $\mathrm{OH}$ and $\mathrm{O}_{2}$ intensity) and Allahabad (in OI $557.7 \mathrm{~nm}$ emission intensity). On this night, the imaging observations at Allahabad were affected by the presence of clouds during 22:0023:18 and 02:00-03:00 IST, and hence this event was not treated before the case of 24-25 June 2009. For the same reason, the removal of long-period tidal trend from $\mathrm{OH}$ and
OI $557.7 \mathrm{~nm}$ intensity data of Allahabad could not be carried out, and the spectral analysis of original intensity data was performed. At Allahabad, $\sim 1.6$ and $\sim 2.2 \mathrm{~h}$ waves were present in the $\mathrm{OH}$ broadband intensity, while the $\sim 1.9,2.6$ and $4.4 \mathrm{~h}$ waves were observed at OI $557.7 \mathrm{~nm}$ heights (see Table 1). A $4.3 \mathrm{~h}$ wave was solely present at $\mathrm{OH}$ and $\mathrm{O}_{2}$ altitudes at Gadanki. As such, the presence of a common wave of period $\sim 4.3 \mathrm{~h}$ can be seen at both locations. Using imaging data, the horizontal propagation characteristics of this wave over Allahabad was estimated - wavelength of $\sim 1194 \pm 54 \mathrm{~km}$, phase speed of $\sim 77 \pm 4 \mathrm{~m} \mathrm{~s}^{-1}$ and propagation towards $339 \pm 4^{\circ}$ azimuth. This wave propagation direction towards the northwest suggests its source to be located southeast of Allahabad. NOAA's OLR data for this day reveal a gigantic convective system located southeast of Allahabad having strength as low as $107 \mathrm{Wm}^{-2}$ and epicentred at $\sim 14^{\circ} \mathrm{N}, 89^{\circ} \mathrm{E}$ in the latitude/longitude grid $\sim 9-21^{\circ} \mathrm{N} / 84$ $94^{\circ}$ E. Assuming $T_{\mathrm{b}} \sim 4 \mathrm{~min}, D_{\mathrm{H}} \sim 900 \mathrm{~km}$ and $D_{\mathrm{Z}} \sim 15 \mathrm{~km}$, the characteristic period of the wave excited by this convective system comes out to be $\sim 4.0 \mathrm{~h}$. Thus, this convective body possibly was the source of this $4.3 \mathrm{~h}$ wave. Overall, these two events observed during 23-25 June 2009 present good examples of the troposphere-stratosphere-mesosphere coupling by convectively generated gravity waves.

\subsection{Case study of 22-23 October 2009}

On the night of 22-23 October 2009, clear sky conditions persisted throughout the night and good nightglow data for more than $7 \mathrm{~h}$ were collected at both locations. On this night, 
the tidal trend present at Allahabad could not be identified, while a terdiurnal tide was seen at Gadanki. At Allahabad, $\sim 2.2$ and $\sim 4.1 \mathrm{~h}$ waves were observed in $\mathrm{OH}$ intensity, while the OI $557.7 \mathrm{~nm}$ layer was marked by a combination of $\sim 2.6$ and $\sim 4.8 \mathrm{~h}$ wave (see Table 1 ). At Gadanki, $\sim 3.7$ and $\sim 4.2 \mathrm{~h}$ waves were observed at $\mathrm{OH}$ and $\mathrm{O}_{2}$ heights, respectively. And it appears that the $4.1 \mathrm{~h}$ wave is the common feature at Gadanki (at $\mathrm{O}_{2}$ heights) and Allahabad (at $\mathrm{OH}$ heights). At Gadanki, the crest of this wave was first seen around 21:50 IST, and later on appeared over Allahabad, at 23:15 IST. For the wave feature with $4.1 \mathrm{~h}$ period seen at both sites to belong to the same wave, the wave source must be placed down south of Gadanki. However, this is not substantiated by its propagation characteristics inferred from Allahabad data. The direction of its propagation as derived from the phase information of off-zenith $\mathrm{OH}$ measurements at Allahabad was towards $134 \pm 3^{\circ}$ azimuth, i.e. southeast, indicating that the wave source may be located northwest of Allahabad. This wave had a phase speed of $166 \pm 10 \mathrm{~m} \mathrm{~s}^{-1}$ and horizontal wavelength of $2447 \pm 141 \mathrm{~km}$. Thus, the presence of this $4.1 \mathrm{~h}$ wave at two locations appears to be a coincidence. NOAA OLR images indicate a convective system located at $\sim 30^{\circ} \mathrm{N}, 42.5^{\circ} \mathrm{E}$ (in latitude/longitude grid of $27-32^{\circ} \mathrm{N}, 40-45^{\circ} \mathrm{E}$ ) northwest of Allahabad. At latitudes smaller than Gadanki, several convective sources were seen in OLR images in latitude/longitude grid of $10^{\circ} \mathrm{S}-10^{\circ} \mathrm{N}, 80$ $95^{\circ} \mathrm{E}$, and possibly were the source of the $3.7 / 4.2 \mathrm{~h}$ waves observed at Gadanki. All the data needed for the ray-tracing analysis were not available, and it can only be conjectured that different convective systems were perhaps the source of the similar waves of $4.1 \mathrm{~h}$ period present at both locations.

\subsection{Case study of 23-24 October 2009}

On this night, the presence of diurnal and semidiurnal tide at $\mathrm{OH}$ and $\mathrm{OI} 557.7 \mathrm{~nm}$ heights, respectively, was observed at Allahabad, while a diurnal tide was seen at $\mathrm{OH}$ and $\mathrm{O}_{2}$ altitudes over Gadanki. Figure 9 presents the variation of residual intensity over Allahabad (top panel) and Gadanki (bottom panel). The waves inferred from residuals are tabulated in Table 1. Over Allahabad, a combination of 1.3, 1.6, 2.3 and $4.0 \mathrm{~h}$ defined the nocturnal variability of $\mathrm{OH}$ intensity, while two waves having period of $\sim 1.6$ and $4.0 \mathrm{~h}$ were present at OI $557.7 \mathrm{~nm}$ heights. From the phase difference at both heights, the $1.6 \mathrm{~h}$ wave was found to be vertically propagating with a phase speed of $\sim 5 \mathrm{~m} \mathrm{~s}^{-1}$. OI $557.7 \mathrm{~nm}$ emission did not show any signature of the 1.3 and $2.3 \mathrm{~h}$ wave. At Gadanki, a mixture of $\sim 1.4,1.8,2.2,3.1$ and $5.6 \mathrm{~h}$ waves were seen in $\mathrm{OH}$ and $\mathrm{O}_{2}$ intensity. Similar waves of period $\sim 1.3$ and $2.2 \mathrm{~h}$ can clearly be observed at the two sites.

The $2.2 \mathrm{~h}$ wave was first seen at Gadanki with its minimum appearing at 20:37-20:42 IST in both $\mathrm{OH}$ and $\mathrm{O}_{2}$ intensity. Later on, the minimum of this wave was observed at Allahabad around midnight $\sim$ 00:06 IST, and was not observed at OI heights. Over Allahabad, the phase of this wave at east,
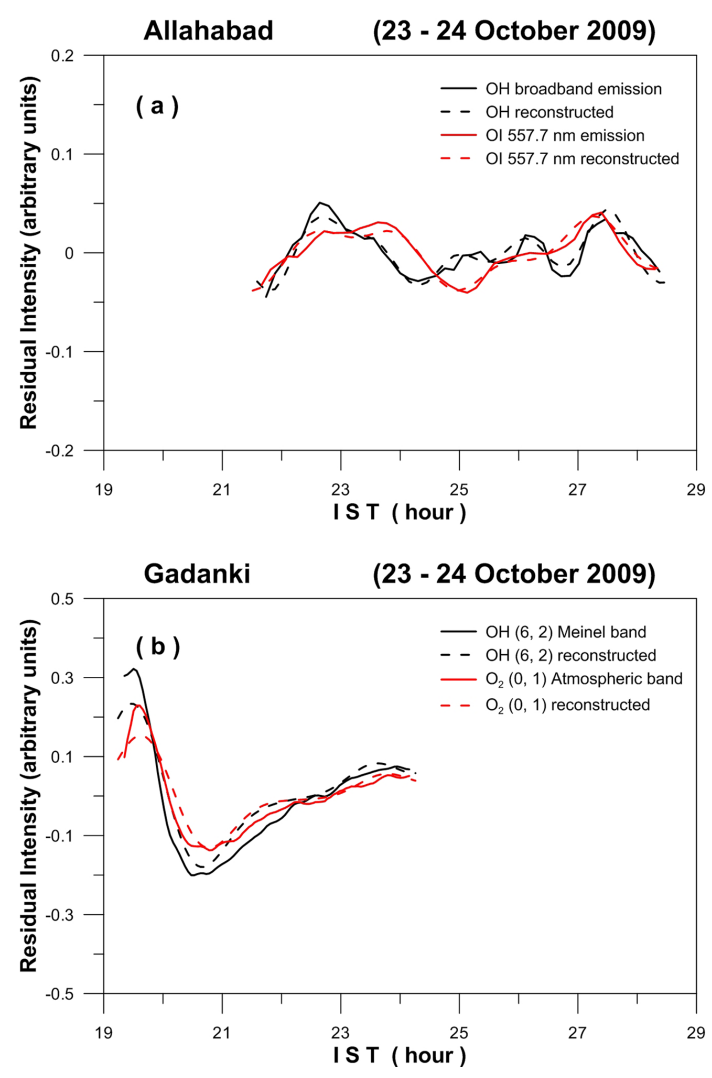

Figure 9. Nocturnal variation of the residual intensity of different emission features over Allahabad (top panel) and Gadanki (bottom panel) on 23-24 October 2009. The broken curve in the individual plots represents the intensity series reconstructed using different spectral components.

north, west and south off-zenith positions was $11,15,-6$ and $-10^{\circ}$, respectively. This wave had a horizontal wavelength of $2625 \pm 41 \mathrm{~km}$, a large phase speed of $331 \pm 5 \mathrm{~m} \mathrm{~s}^{-1}$ and was found to travel along the $57 \pm 1^{\circ}$ azimuth, indicating a source located towards the southwest. According to NOAA OLR data and KALPANA-1 infrared images (not shown here), there was convective activity at smaller latitude than at Gadanki. The strongest of them was situated at $\sim 2.5^{\circ} \mathrm{N}, 60^{\circ} \mathrm{E}$ with OLR strength of $141 \mathrm{~W} \mathrm{~m}^{-2}$. As this lay nearly inline with the wave propagation direction indicated by imaging observations at Allahabad, it might be the source of this $2.2 \mathrm{~h}$ wave. The $\mathrm{m}^{2}$ profile (obtained from SABER temperature profile and HWM-07 wind predictions, as before; see Fig. 10) shows a region of (i) positive $\mathrm{m}^{2}$ between 88 and $97 \mathrm{~km}$ sandwiched between two negative regions at Gadanki; (ii) negative $\mathrm{m}^{2}$ between 89 and $95 \mathrm{~km}$, and positive $\mathrm{m}^{2}$ between 82 and $88 \mathrm{~km}$ at Allahabad. At Gadanki, the $88-97 \mathrm{~km}$ regime (marked by positive $\mathrm{m}^{2}$, and containing partially the $\mathrm{OH}$ layer and fully the $\mathrm{O}_{2}$ layer) may have acted as a duct. Over Allahabad, a negative $\mathrm{m}^{2}$ region in $89-95 \mathrm{~km}$ and a positive $\mathrm{m}^{2}$ region between 82 and $88 \mathrm{~km}$ may account for the observation of this $2.2 \mathrm{~h}$ wave at $\mathrm{OH}$ heights and non- 

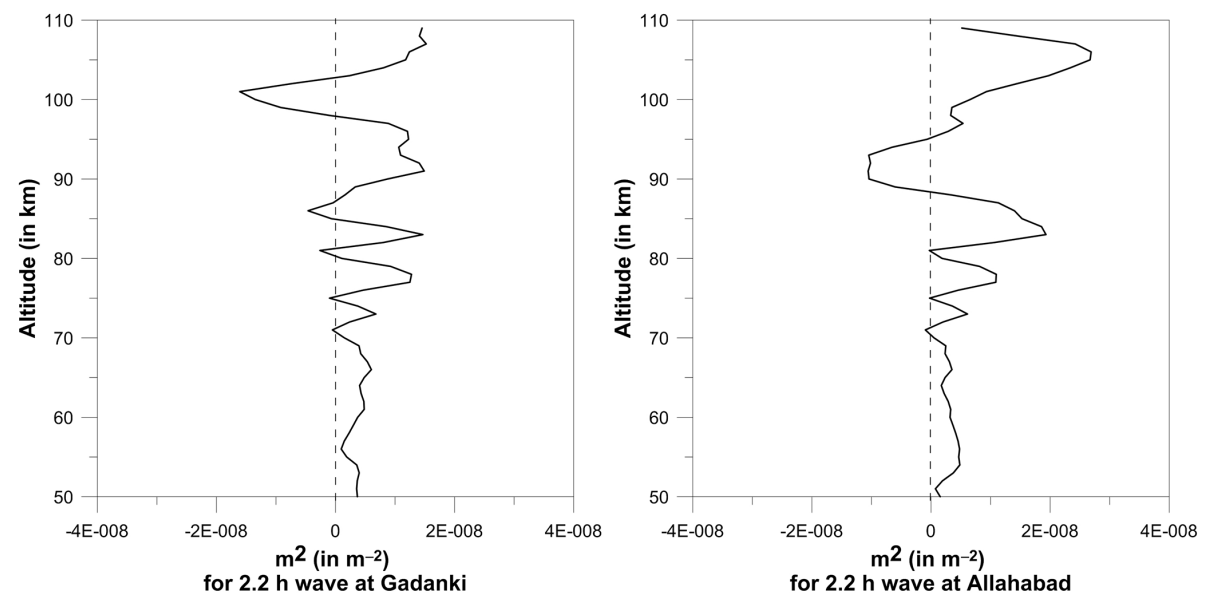

Figure 10. Altitude variation of the squared vertical wave number $\left(\mathrm{m}^{2}\right)$ for $2.2 \mathrm{~h}$ wave at Gadanki (left panel) and Allahabad (right panel).

existence at OI $557.7 \mathrm{~nm}$ layer. Thus, the ducted propagation of this $2.2 \mathrm{~h}$ wave in the $2-27^{\circ} \mathrm{N}$ latitude range can be conjectured. Another possibility is that the direction of this wave underwent a slight change in the course of its propagation to Allahabad due to the effect of background wind. The presence of ducting conditions was also corroborated by the imaging observations at Allahabad.

Image data of $\mathrm{OH}$ broadband emissions revealed smallscale wave motions propagating towards the north in $\mathrm{OH}$ broadband emissions (shown in Fig. 11); however, OI $557.7 \mathrm{~nm}$ images did not record any signature of this wave. A well-defined wave pattern characterized by highly coherent phase structures can clearly be seen in the $\mathrm{OH}$ image. The wave display lasted for nearly an hour during 03:0003:46 IST of 24 October 2009. Overall, the observations reveal small- as well as large-scale wave propagation at $\mathrm{OH}$ heights along the south-north direction, suggesting (i) the wave source to be located towards the south and (ii) their ducted propagation.

\subsection{Case study of 15-16 April 2010}

On 15-16 April 2010, around $8 \mathrm{~h}$ of continuous observations resulted as a consequence of the favourable observing conditions during the night at both locations. At Allahabad, the diurnal and terdiurnal tide was respectively present at $\mathrm{OH}$ and $\mathrm{OI} 557.7 \mathrm{~nm}$ altitudes, while the $\mathrm{OH}$ and $\mathrm{O}_{2}$ intensity variation over Gadanki was affected by a semidiurnal tide. The variation of residual intensity at the two locations is shown in Fig. 12, and the waves observed are summarized in Table 1. At Allahabad, $\sim 1.9$ and $\sim 2.6 \mathrm{~h}$ waves were observed at $\mathrm{OH}$ emission altitudes, while the $\mathrm{OI} 557.7 \mathrm{~nm}$ intensity variations were defined by $\sim 2.2$ and $\sim 3.7 \mathrm{~h}$ waves. At Gadanki, the $\sim 3.5 \mathrm{~h}$ wave was the only spectral component present in both $\mathrm{OH}$ and $\mathrm{O}_{2}$ intensity. Here, the $3.5 \mathrm{~h}$ wave seems to be the common wave feature. At Allahabad, the minimum of this wave appeared around 21:54 IST in OI

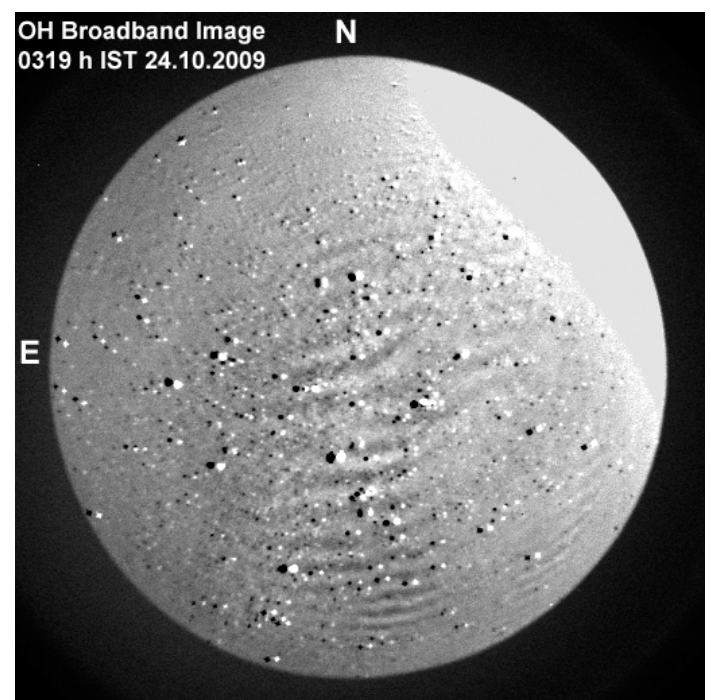

Figure 11. Sample image of $\mathrm{OH}$ broadband emission over Allahabad on 23-24 October 2009 with northward-propagating smallscale waves.

intensity, while its minimum was observed simultaneously around 21:48 IST at $\mathrm{OH}$ and $\mathrm{O}_{2}$ altitudes at Gadanki. At Allahabad, the absence of this wave in the $\mathrm{OH}$ layer (placed below OI $557.7 \mathrm{~nm}$ layer) may be due to the presence of a duct. The phase of this wave in the east, north, west and south off-zenith positions at Allahabad was 79, 71, 70 and $77^{\circ}$, respectively. As the field of view of imager subsumes a circle of diameter of $\sim 200-220 \mathrm{~km}$ at the MLT heights and the phase differences between two off-zenith measurements is very small $\left(\sim 9^{\circ}\right.$ or less), such phase information is ideally not suitable for estimation of the horizontal wave characteristics. Nevertheless, the propagation direction of wave was estimated and it was found to travel approximately towards an azimuth of $125 \pm 7^{\circ}$, suggesting the source to be located approximately northwest of Allahabad. In the NOAA OLR 

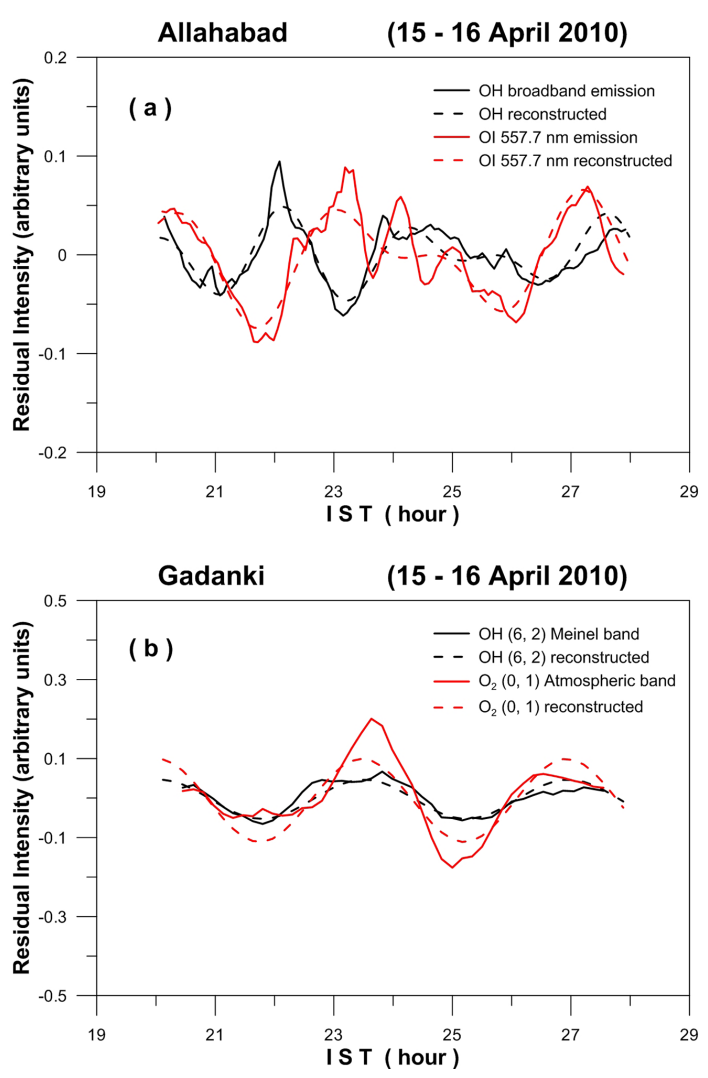

Figure 12. As Fig. 9, but for 15-16 April 2009.

images (not shown here), several convective systems in latitude/longitude sector of $35-50^{\circ} \mathrm{N}, 65-90^{\circ} \mathrm{E}$ were observed. The strongest of them lay at $45^{\circ} \mathrm{N}, 78^{\circ} \mathrm{E}$ located northwest of Allahabad, and possibly generated this $2.2 \mathrm{~h}$ wave. A sequence of KALPANA-1 images (not shown here) also indicate the presence of strong forcings in the latitude/longitude range of $30-50^{\circ} \mathrm{N}, 70-85^{\circ} \mathrm{E}$.

\section{Discussion}

The investigations presented above diagnose the propagation of gravity waves over large distances over the Indian subcontinent. At times the similar wave seen at Allahabad and Gadanki originated from a common source. On 23-24 and 24-25 June 2009, a 4.3-4.5 h common wave was observed that originated from a mesoscale convective system located at $12.5^{\circ} \mathrm{N}, 90^{\circ} \mathrm{E}$. This wave propagated over $14^{\circ} \times 10^{\circ}$ latitude/longitude grid and was seen at Allahabad and Gadanki. Similarly, a $2.2 \mathrm{~h}$ common wave was seen on 23-24 October 2009 that had its origin at $2.5^{\circ} \mathrm{N}, 60^{\circ} \mathrm{E}$, and travelled over latitude/longitude grid of $24^{\circ} \times 22^{\circ}$. This wave was first observed at Gadanki and was later seen at Allahabad. Assisted by NOAA OLR contour images and KALPANA-1 infrared images, convective activity appears to be the source of these waves. At other times, the presence of a similar wave at both locations was possibly a coincidence (for example on 22-23 October 2009). Our findings put the $2.2-4.5 \mathrm{~h}$ similar waves in the class of large-scale gravity waves. Typically, their horizontal wavelengths lay in the range of 1194$2746 \mathrm{~km}$, and the phase speeds varied from 77 to $331 \mathrm{~m} \mathrm{~s}^{-1}$. Large-scale gravity waves of such horizontal scales, phase speeds and periods have earlier been reported in the literature. Zhang et al. (1993) investigated the characteristics of gravity waves over Puerto Rico $\left(17^{\circ} 57^{\prime} \mathrm{N}, 66^{\circ} 52^{\prime} \mathrm{W}\right)$ using the database of simultaneous multi-directional measurements of $\mathrm{O}_{2}(0,1)$ Atmospheric band intensity and temperature by Mesopause Oxygen Rotational Temperature Imager (MORTI) during April-May 1989, and found (i) the apparent periods between 45 and $360 \mathrm{~min}$, (ii) the apparent speeds between 48 and $282 \mathrm{~m} \mathrm{~s}^{-1}$, and (iii) the horizontal wavelengths between 200 and $2900 \mathrm{~km}$. On 3-4 May 1989, these authors observed a gravity wave (similar to our observations on 24-25 June 2009) having period of $\sim 4.6 \mathrm{~h}$, phase speed of $\sim 174 \mathrm{~m} \mathrm{~s}^{-1}$ and horizontal wavelength of $\sim 2896 \mathrm{~km}$. Using $\mathrm{OH}(6,2)$ Meinel band intensity and temperature measurements in conjunction with a middle and upper atmosphere radar (MU radar) observations over Shigaraki $\left(34.9^{\circ} \mathrm{N}, 136.1^{\circ} \mathrm{E}\right)$, Japan during 1994-1995, Takahashi et al. (1999) reported gravity waves having periods of $2-9 \mathrm{~h}$ and horizontal wavelengths of $500-3000 \mathrm{~km}$. Using Spectral Airglow Thermal Imager (SATI) instrument measurements of $\mathrm{OH}$ and $\mathrm{O}_{2}$ airglow over Resolute Bay $\left(74.7^{\circ} \mathrm{N}, 94.9^{\circ} \mathrm{W}\right)$ and Eureka $\left(80.0^{\circ} \mathrm{N}, 86.3^{\circ} \mathrm{W}\right)$, Canada during November 2001, Cho et al. (2010) investigated the horizontal propagation characteristics of gravity waves, and observed a wave of period of $\sim 4.5 \mathrm{~h}$ having horizontal wavelength of 2096 and $3522 \mathrm{~km}$ at $\mathrm{OH}$ heights over Eureka and Resolute Bay, respectively, on 15 November 2007.

It can also be noted that the convective wave sources are not exactly aligned opposite to the wave propagation direction. Simulation studies by Walterscheid et al. (2001) on the generation of small-scale gravity waves in the MLT region by intense deep convection in the troposphere show that (i) such convection can excite ducted gravity waves which can travel to large distances ( $\sim$ few $1000 \mathrm{~km})$ from their origin, and (ii) their propagation can be affected by background winds as well as the horizontal variations in the thermal structure of the MLT region.

\section{Summary and conclusions}

Coordinated measurements of the MLT region nightglow at Allahabad and Gadanki in the period June 2009 to May 2010 were used to investigate the propagation of gravity waves over large distances in the Indian subcontinent. On 23-24 and 24-25 June 2009 and 23-24 October 2009, an identical wave (period ranging from 2.2 to $4.5 \mathrm{~h}$ ) was observed at both locations that shared a common source. NOAA OLR contour images and KALPANA-1 infrared images indicate a 
mesoscale convective system to be the source of the common wave on these nights. Using imaging data over Allahabad, the propagation characteristics of similar waves present at the two stations were estimated. Typically, the waves had large horizontal wavelength $(\sim 1194-2746 \mathrm{~km})$ and their phase speed lay in the $77-331 \mathrm{~m} \mathrm{~s}^{-1}$ range. SABER/TIMED temperature profiles and Horizontal Wind Model (HWM$07)$ estimates were used to perform the $\mathrm{m}^{2}$ profile analysis. Such analysis suggests the ducted propagation of the common waves. Assisted by the available literature (cited in the Introduction), this study invokes the capability of multistation studies in investigating the long-distance propagation of gravity waves.

Acknowledgements. Funds for airglow research at the Indian Institute of Geomagnetism are being provided by Department of Science and Technology (DST), Govt of India, New Delhi and Indian Space Research Organization (ISRO), Bangalore (under CAWSES India Phase II Programme during 2010-2013). OLR images provided by the NOAA-ESRL Physical Sciences Division, Boulder Colorado from their website at http://www.esrl.noaa.gov/ psd/, KALPANA-1 images downloaded from MOSDAC/ISRO, and SABER/TIMED temperature profiles obtained from http://saber. gats-inc.com are gratefully acknowledged. N. Parihar is sincerely grateful to the referees, editor and S. Gurubaran for their esteemed suggestions. N. Parihar is thankful to International Centre for Theoretical Physics for Junior Associateship.

The topical editor C. Jacobi thanks J. V. Bageston and two anonymous referees for help in evaluating this paper.

\section{References}

Bageston, J. V., Wrasse, C. M., Batista, P. P., Hibbins, R. E., C Fritts, D., Gobbi, D., and Andrioli, V. F.: Observation of a mesospheric front in a thermal-Doppler duct over King George Island, Antarctica, Atmos. Chem. Phys., 11, 12137-12147, doi:10.5194/acp11-12137-2011, 2011.

Chimonas, G. and Hines, C. O.: Doppler ducting of atmospheric gravity waves, J. Geophys. Res., 91, 1219-1230, 1986.

Cho, Y. -M., Shepherd, M. G., and Shepherd, G. G.: Wave perturbations in the MLT at high northern latitudes in winter, observed by two SATI instruments, Adv. Space Res., 45, 45-55, 2010.

Ding, F., Wan, W., and Yuan, H.: The influence of background winds and attenuation on the propagation of atmospheric gravity waves, J. Atmos. Solar-Terres. Phys., 65, 857-869, 2003.

Drob, D. P., Emmert, J. T., Crowley, G., Picone, J. M., Shepherd, G. G., Skinner, W., Hays, P., Niciejewski, R. J., Larsen, M., She, C. Y., Meriwether, J. W., Hernandez, G., Jarvis, M. J., Sipler, D. P., Tepley, C. A., O'Brien, M. S., Bowman, J. R., Wu, Q., Murayama, Y., Kawamura, S., Reid, I. M., and Vincent, R. A.: An empirical model of the Earth's horizontal wind fields: HWM07, J. Geophys. Res., 113, A12304, doi:10.1029/2008JA013668, 2008.

Ejiri, M. K., Shiokawa, K., Ogawa, T., Igarashi, K., Nakamura, T., and Tsuda, T.: Statistical study of short-period gravity waves in $\mathrm{OH}$ and $\mathrm{OI}$ nightglow images at two separated sites, J. Geophys. Res., 108, 4679, doi:10.1029/2002JD002795, 2003.
Fritts, D. C. and Alexander, M. J.: Gravity wave dynamics and effects in the middle atmosphere, Rev. Geophys., 41, 1003, doi:10.1029/2001RG000106, 2003.

Fritts, D. C. and Yuan, L.: An Analysis of Gravity Wave Ducting in the Atmosphere: Eckart's Resonances in Thermal and Doppler Ducts, J. Geophys. Res., 94, 18455-18466, 1989.

Hines, C. O. and Tarasick, D. W.: Airglow response to vertically standing gravity waves, Geophys. Res. Lett., 21, 2729-2732, 1994.

Isler, J. R., Taylor, M. J., and Fritts, D. C.: Observational evidence of wave ducting and evanescence in the mesosphere, J. Geophys Res., 102, 26301-26313, 1997.

Kubota, M., Kawamura, S., Abo, M., Koizumi, Y., Murayama, Y., Yamamori, M., Shiokawa, K., Otsuka, Y., Uchiumi, M., Igarashi, K., Abe, T., Oyama, K.-I., and Iwagami, N.: A fastpropagating, large-scale atmospheric gravity wave observed in the WAVE2004 campaign, J. Geophys. Res., 111, D21110, doi:10.1029/2005JD006788, 2006.

Liebmann, B. and Smith, C. A.: Description of a complete (interpolated) outgoing longwave radiation dataset, B. Am. Meteorol Soc., 77, 1275-1277, 1996.

Lomb, N. R.: Least-squares frequency analysis of unequally spaced data, Astrophys. Space Sci., 39, 447-462, 1976.

Medeiros, A. F., Takahashi, H., Buriti, R. A., Pinheiro, K. M., and Gobbi, D.: Atmospheric gravity wave propagation direction observed by airglow imaging in the South American sector, J. Atmos. Solar-Terres. Phys., 67, 1767-1773, 2005.

Medeiros, A. F., Takahashi, H., Buriti, R. A., Fechine, J., Wrasse, C. M., and Gobbi, D.: MLT gravity wave climatology in the South America equatorial region observed by airglow imager, Ann. Geophys., 25, 399-406, 2007, http://www.ann-geophys.net/25/399/2007/.

Mertens, C. J., Mlynczak, M. G., Lopez-Puertas, M., Wintersteiner, P. P., Picard, R. H., Winick, J. R., Gordley, L. L., and Russell III, J. M.: Retrieval of mesospheric and lower thermospheric kinetic temperature from measurements of $\mathrm{CO}_{2} 15 \mu \mathrm{m}$ Earth Limb Emission under non-LTE conditions, Geophys. Res. Lett., 28, 1391-1394, doi:10.1029/2000GL012189, 2001.

Mukherjee, G. K., Pragati Shikha, R., Parihar, N., Ghodpage, R., and Patil, P. T.: Studies of the wind filtering effect of gravity waves observed at Allahabad $\left(25.45^{\circ} \mathrm{N}, 81.85^{\circ} \mathrm{E}\right)$ Earth Planets Space, 62, 309-318, 2010.

Nielsen, K., Taylor, M. J., Hibbins, R. E., Jarvis, M. J., and Russell, J. M. III: On the nature of short-period mesospheric gravity wave propagation over Halley, Antarctica, J. Geophys. Res., 117, D05124, doi:10.1029/2011JD016261, 2012.

Noxon, J. F.: Effect of internal gravity waves upon night airglow temperatures, Geophys. Res. Lett., 5, 25-27, 1978.

Parihar, N. and Mukherjee, G. K.: A case study of gravity waves observed in $\mathrm{OH}$ rotational temperatures at Kolhapur $\left(16.8^{\circ} \mathrm{N}\right.$, 74.1 ${ }^{\circ}$ E), India, Indian J. Radio Space Phys., 43, 67-74, 2014.

Parihar, N., Taori, A., Gurubaran, S., and Mukherjee, G. K.: Simultaneous measurement of OI $557.7 \mathrm{~nm}, \mathrm{O} 2(0,1)$ Atmospheric Band and $\mathrm{OH}(6,2)$ Meinel Band nightglow at Kolhapur $\left(17^{\circ} \mathrm{N}\right)$, India, Ann. Geophys., 31, 197-208, doi:10.5194/angeo-31-1972013, 2013.

Prakash, S., Mahesh, C., and Gairola, R. M.: Large-scale precipitation estimation using Kalpana-1 IR measurements and its valida- 
tion using GPCP and GPCC data, Theor. Appl. Climatol., 106, 283-293, doi:10.1007/s00704-011-0435-7, 2011.

Preusse, P., Eidmann, G., Eckermann, S. D., Schaeler, B., Spang, R., and Offermann, D.: Indications of convectively generated gravity waves in CRISTA temperatures, Adv. Space Res., 27, 16531658, 2001.

Smith, S. M., Mendillo, M., Baumgardner, J., and Clark, R. R.: Mesospheric gravity wave imaging at a subauroral site: First results from Millstone Hill, J. Geophys. Res., 105, 27119-27130, 2000.

Smith, S. M., Taylor, M. J., Swenson, G. R., She, C. Y., Hocking, W., Baumgardner, J., and Mendillo, M.: A multidiagnostic investigation of the mesospheric bore phenomenon, J. Geophys. Res., 108, 1083, doi:10.1029/2002JA009500, 2003.

Snively, J. B., Pasko, V. P., Taylor, M. J., and Hocking, W. K.: Doppler ducting of short-period gravity waves by midlatitude tidal wind structure, J. Geophys. Res., 112, A03304, doi:10.1029/2006JA011895, 2007.

Stockwell, R. G. and Lowe, R. P.: Airglow imaging of gravity waves 1. Results from a small network of $\mathrm{OH}$ nightglow scanning imagers, J. Geophys. Res., 106, 17185-17203, 2001.

Suzuki, S., Shiokawa, K., Otsuka, Y., Kawamura, S., and Murayama, Y.: Evidence of gravity wave ducting in the mesopause region from airglow network observations, Geophys. Res. Lett., 40, 601-605, 2013.

Takahashi, H., Batista, P. P., Sahai, Y., and Clemesha, B. R.: Atmospheric wave propagations in the mesopause region observed by $\mathrm{OH}(8,3)$ band, $\mathrm{NaD}, \mathrm{O}_{2} \mathrm{~A}(8645 \mathrm{~A})$ band and OI 5577A nightglow emissions, Planet. Space Sci., 33, 381-384, 1985.

Takahashi, H., Batista, P. P., Buriti, R. A., Gobbi, D., Nakamura, T., Tsuda, T., and Fukao, S.: Response of the airglow OH emission, temperature and mesopause wind to the atmospheric wave propagation over Shigaraki, Japan, Earth Planet. Space, 51, 863-875, 1999.

Taori, A., Dashora, N., Raghunath, K., Russell III, J. M., and Mlynczak, M. G.: Simultaneous mesosphere thermosphere ionosphere parameter measurements over Gadanki $\left(13.5^{\circ} \mathrm{N}, 79.2^{\circ} \mathrm{E}\right)$ : First results, J. Geophys. Res., 116, A07308, doi:10.1029/2010JA016154, 2011.
Taylor, M. J., Turnbull, D. N., and Lowe, R. P.: Spectrometric and imaging measurements of a spectacular gravity wave event observed during the ALOHA-93 campaign, Geophys. Res. Lett., 22, 2849-2852, 1995.

Vadas, S. L. and Fritts, D. C.: Gravity wave radiation and mean responses to local body forces in the atmosphere, J. Atmos. Sciences, 58, 2249-2279, 2001.

Vadas, S. L., Yue, J., She, C.-Y., Stamus, P. A., and Liu, A. Z.: A model study of the effects of winds on concentric rings of gravity waves from a convective plume near Fort Collins on 11 May 2004, J. Geophys. Res., 114, D06103, doi:10.1029/2008JD010753, 2009.

Venkat Ratnam, M., Tsuda, T., Shiotani, M., and Fujiwara, M.: New Characteristics of the Tropical Tropopause Revealed by CHAMP/GPS Measurements, Scientific Online Lett. Atmos., 1, 185-188, doi:10.2151/sola.2005-048, 2005.

Vincent, R. A., Alexander, M. J., Dolman, B. K., MacKinnon, A. D., May, P. T., Kovalam, S., and Reid, I. M.: Gravity wave generation by convection and momentum deposition in the mesosphere-lower thermosphere, J. Geophys. Res., 118, 62336245, doi:10.1002/jgrd.50372, 2013.

Walterscheid, R. L., Schubert, G., and Brinkman, D. G.: Small-scale gravity waves in the upper mesosphere and lower thermosphere generated by deep tropical convection, J. Geophys. Res., 106, 31825-31832, 2001.

Wrasse, C. M., Nakamura, T., Takahashi, H., Medeiros, A. F., Taylor, M. J., Gobbi, D., Denardini, C. M., Fechine, J., Buriti, R. A., Salatun, A., Suratno, Achmad, E., and Admiranto, A. G.: Mesospheric gravity waves observed near equatorial and low-middle latitude stations: wave characteristics and reverse ray tracing results, Ann. Geophys., 24, 3229-3240, 2006, http://www.ann-geophys.net/24/3229/2006/.

Zhang, S. P., Peterson, R. N., Wiens, R. H., and Shepherd, G. G.: Gravity waves from $\mathrm{O}_{2}$ nightglow during the AIDA'89 campaign I: emission rate/temperature observations, J. Atmos. Terres. Phys., 55, 355-375, 1993. 